\title{
Convective Snowfalls Linked to the Interaction of a Boundary-Layer Front with a Mesoscale Cyclone Near Terra Nova Bay, Antarctica
}

\author{
Roberto Bove • Grigioni Paolo
}

Received: 21 July 2008 / Accepted: 24 February 2009 / Published online: 9 April 2009

(C) The Author(s) 2009. This article is published with open access at Springerlink.com

\begin{abstract}
During the XXII Italian expedition in Antarctica, in the summer of 2007, severe weather conditions associated with deep convective instability and heavy coastal precipitation occurred around the Terra Nova Bay area in the presence of an upper level trough and energetic katabatic winds flowing from the Ross Ice Shelf over the open sea. In this case study we document an example of boundary-layer frontal movement across the Ross Sea and mesocyclone development in conjunction with the frontal movement. A westward fast moving boundary-layer front, generated by the leftward turning katabatic airstream to the east of Ross Island, was observed propagating as a baroclinic wave disturbance in an easterly direction across the Ross Sea, merging later with a mesocyclone approaching Terra Nova Bay from offshore. The observed inertial trajectory and an estimation of the radius of curvature suggest that the vigorous katabatic airstream was sustained by the strengthening of a surface mesocyclonic circulation settled over the north-eastern Ross Ice Shelf, triggered by a sub-synoptic upper level trough passing over the area. We hypothesise that baroclinic instability in the low levels plays an important role in the development of a mesoscale vortex and for triggering convective precipitation.
\end{abstract}

Keywords Antarctica - Boundary-layer cold front · Katabatic wind . Mesoscale cyclogenesis $\cdot$ Snowfall

\footnotetext{
R. Bove $(\bowtie)$

Italian National Weather Service, Short-Medium Range Forecasts Department, Centro Nazionale di Meteorologia e Climatologia Aeronautica (CNMCA), military airport "M. De Bernardi", Via di Pratica di Mare, 45, 00040 Pomezia (RM), Italy e-mail: bove@meteoam.it

G. Paolo

Ente per le Nuove Tecnologie, l'Energia e l'Ambiente, (ENEA)-CLIM-OSS,

S.P. Anguillarese, 301, 00060 S.M. di Galeria (RM), Italy
} 


\section{Introduction}

Previous studies in East Antarctica, and in particular over the Ross Sea, based on automatic weather stations (AWS) and satellite images (Bromwich 1989b, 1990; Carrasco and Bromwich 1995; Carrasco et al. 1997), or in simulating the near-surface wind regime (Parish and Bromwich 1987, 1988; O'Connor and Bromwich 1988), have demonstrated that subsynoptic-scale disturbances and mesoscale cyclogenesis occur in areas where the confluence of cold air masses arriving from the interior of the continent produce strong outbreaks of katabatic flow over the open ocean. These shallow disturbances, of horizontal dimension of the order of a few hundred kilometres, grow within the polar air mass and are not associated with a jet streak in the upper levels, as is more typically the case with frontal zones in the classic "polar low" (Businger 1985).

Preferential confluence zones characterized by strong katabatic outbreaks over the open sea, where frequent mesocyclones have been observed, are separately seen around Terra Nova Bay, Byrd Glacier and the Siple Coast (Parish and Bromwich 1987, 1991; Carrasco and Bromwich 1994). Climatological studies have shown that a high percentage of cyclones forming on the Byrd Glacier occur in conjunction with those in Terra Nova Bay, with a noticeable tendency for simultaneous cyclogenesis that becomes significant in both areas, in particular during the month of January (Bromwich 1990; Carrasco et al. 2003). Many authors have identified baroclinic instability as the principle mechanism responsible for such disturbances, especially during the early stage of development, when the cold continental air moving over the warmer maritime air forms a boundary-layer baroclinic zone with a strong thermal contrast (Bromwich 1986; Carrasco and Bromwich 1993, 1994). Other mechanisms contribute to the development and time evolution of mesoscale cyclones, such as air-sea interaction and the transport of sensible and latent heat from the relatively warm water to the air above (Emanuel and Rotunno 1989; Bromwich 1989b, 1991), as well as conditional instability of the second kind (CISK), by convective heating and strong low-level convergence. The reduced static stability near the surface due to diabatic heating of the atmosphere can be responsible for a faster growing disturbance with a shorter wavelength (Rasmussen 1979; Craig and Cho 1989). On the other hand, mesoscale cyclogenesis forming to the lee of Ross Island occurs with weak baroclinicity, and strong shear and stretching vorticity under negligible synoptic forcing. Detailed investigations, confirmed by numerical simulations, show that the predominant airflow around the Ross Island region is strongly dependent on the topography, which plays an important role in the formation and development of mesoscale cyclogenesis in the area (Bromwich 1991; Carrasco and Bromwich 1993, 1994, 1996; Carrasco et al. 2003; Gallée 1995, 1996; Heinemann and Klein 2003). The cold, strongly stable, air advected northward against Ross Island tends to pile up at the base of the escarpment, generating anomalous horizontal pressure gradients, which then result in a barrier wind along the Trans Antarctic Mountains (Schwerdtfeger 1984; O'Connor and Bromwich 1988). The katabatic outbreak flowing from the Ross Ice Shelf is forced to split into two branches around Ross Island, with the eastern branch curving anticyclonically as it moves northward and away from the island-induced pressure gradient. Similar conditions have been found in the region of Bransfield Strait on the Antarctic Peninsula, and in the Northern Hemisphere over the Norwegian Sea (Parish and Schwerdtfeger 1977; Moore and Renfrew 2005). As the flow reaches the end of a topographic barrier it moves from geostrophic to gradient-wind balance, becoming super-geostrophic as a result of the anticyclonic curvature (Moore and Renfrew 2005).

Energetic katabatic winds have been observed propagating for great distances when "anchored" to a pronounced regional pressure gradient due to a synoptic-scale circulation 
in the neighbourhood, thus following a geostrophic adjustment (Bromwich et al. 1992). In this paper, the interaction of a vigorous katabatic outbreak propagating as a baroclinic wave disturbance across the Ross Sea and along the coast of Victoria Land, with a well-developed mesoscale system approaching Terra Nova Bay, is discussed.

\section{Case Study}

\subsection{Satellite Detection and AWS Observations}

The period under investigation spans the period 14-15 January 2007, with the event occurring over the western region of the Ross Sea, in the Terra Nova Bay area.

Meteorological data, including satellite images and surface observations collected by the network of automatic weather stations (AWS) (Fig. 1) over the Ross Sea and Ross Ice Shelf are examined. The infrared (IR) composite satellite image (Fig. 2a) taken at 0000 UTC, January 14, showed a developing vortex (L1) with a weak low-cloud spiral approaching offshore from around the central Victoria Land coastline. Another mesoscale cyclone (L2), although less well defined, was located to the north-east of the Ross Ice Shelf, where the area was covered by extensive fog and thick low cloud. The subsequent composite satellite image, at 0600 UTC (Fig. 2b), depicts the well-defined comma vortex (L1) moving from the north-east towards the coast of Terra Nova Bay. (The term comma cloud is seen in the distinctive shape of the cloud signature on the satellite image).

From Fig. 2b, there is clear evidence of a large amount of moisture funnelling through the David Cauldron (the ice-fall west of the Drygalski Ice Tongue) onto the Reeves Neve. A large moisture "surge" supplied by the easterly inflow, along the coast of the central Victoria Land and from the maritime environment, was responsible for the onset of another mesoscale cyclone (L3) forming on the Reeves Neve (Fig. 2b, c). The subsequent displacement of the vortex (L2) northward is documented by the satellite image sequence Fig. 2a-d. The signature of a katabatic surge from Byrd Glacier was recorded at the closest AWS 8934 (Marilyn), where the wind speed increased at 0400 UTC, and at AWS 8913 (Schwerdtfeger), where the wind speed increased at 1100 UTC, January 14. The wind speed increase was accompanied by a shift in direction to a southerly and with an abrupt temperature fall (Fig. 3a). A band of convective cloud, made up of cumulus and cumulonimbus, was detected as a distinctive feature on the satellite image (Fig. 2d) around the centre of the vortex (L1), indicating enhanced convection. Figure $2 \mathrm{~d}$ suggests that the cloud spiral associated with the vortex (L1) underwent an unexpected translation westward in a direction approximately perpendicular to the coast of Terra Nova Bay, with the spiraliform feature no longer symmetric in shape. It is inferred from this that the forcing of the advancing anticyclonic katabatic airstream caused the cloud band to turn in this direction.

The cloud spiral of the cyclone (L1) degenerated in a frontal-like structure, with the presence of a band of convective clouds. Thick cloud in the middle and upper levels associated with the deep vortex L1 are revealed in the satellite image by their distinctive brighter signature, in comparison with the dark or grey tones appearing in the shallow vortex (L2). Evident in the last satellite image (Fig. 2d) is the signature of the katabatic drainage through the Byrd Glacier where the warm signature, showing up as a dark stripe, is due to turbulent vertical mixing and blowing snow transport within the stable layer (Bromwich 1989a). Unfortunately the gaps between consecutive satellite images impede study of the cloud evolution in detail. Light to moderate precipitation affecting Terra Nova Bay at 1800 UTC, January 14, suddenly 


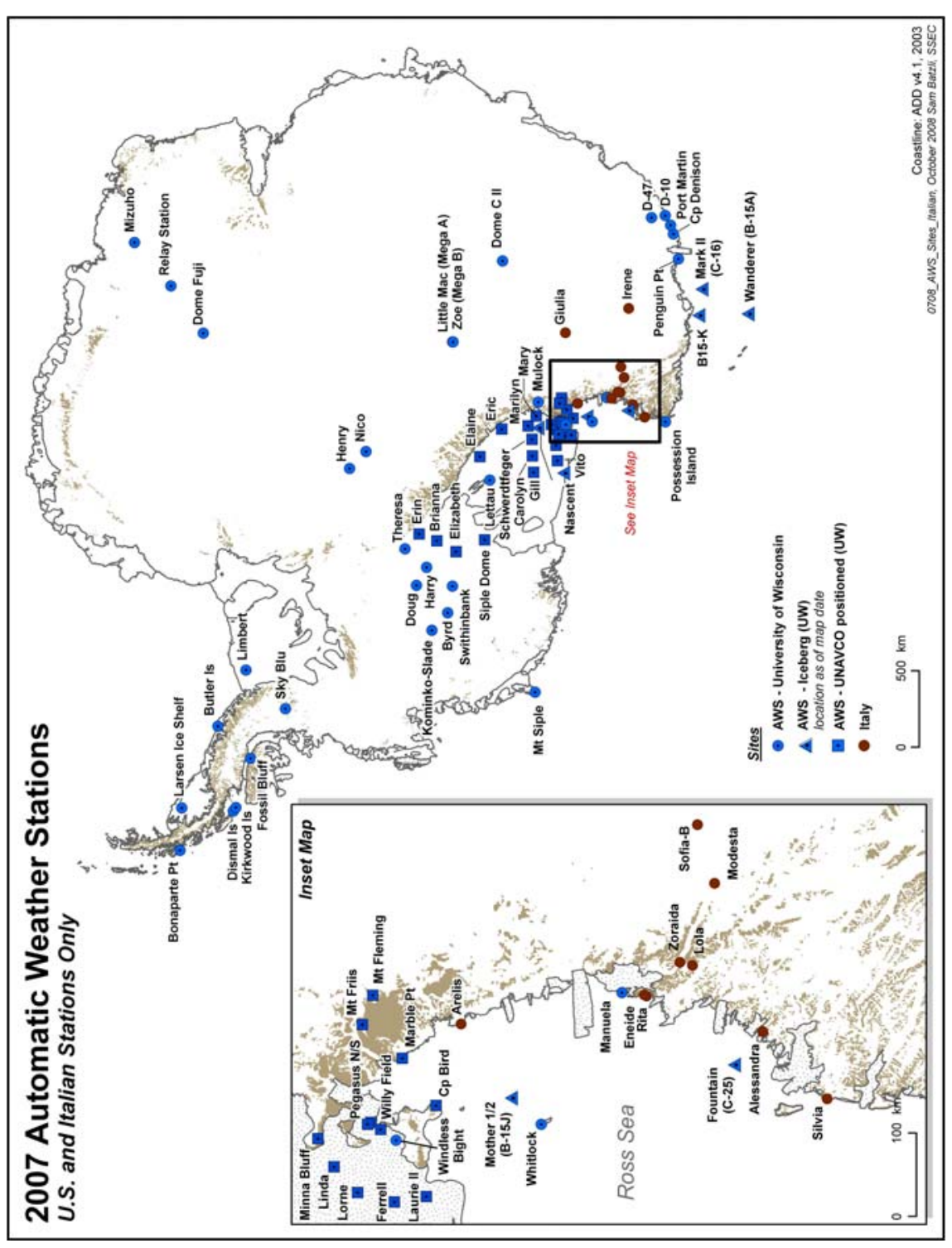

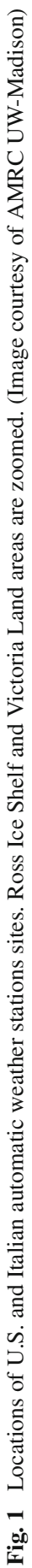



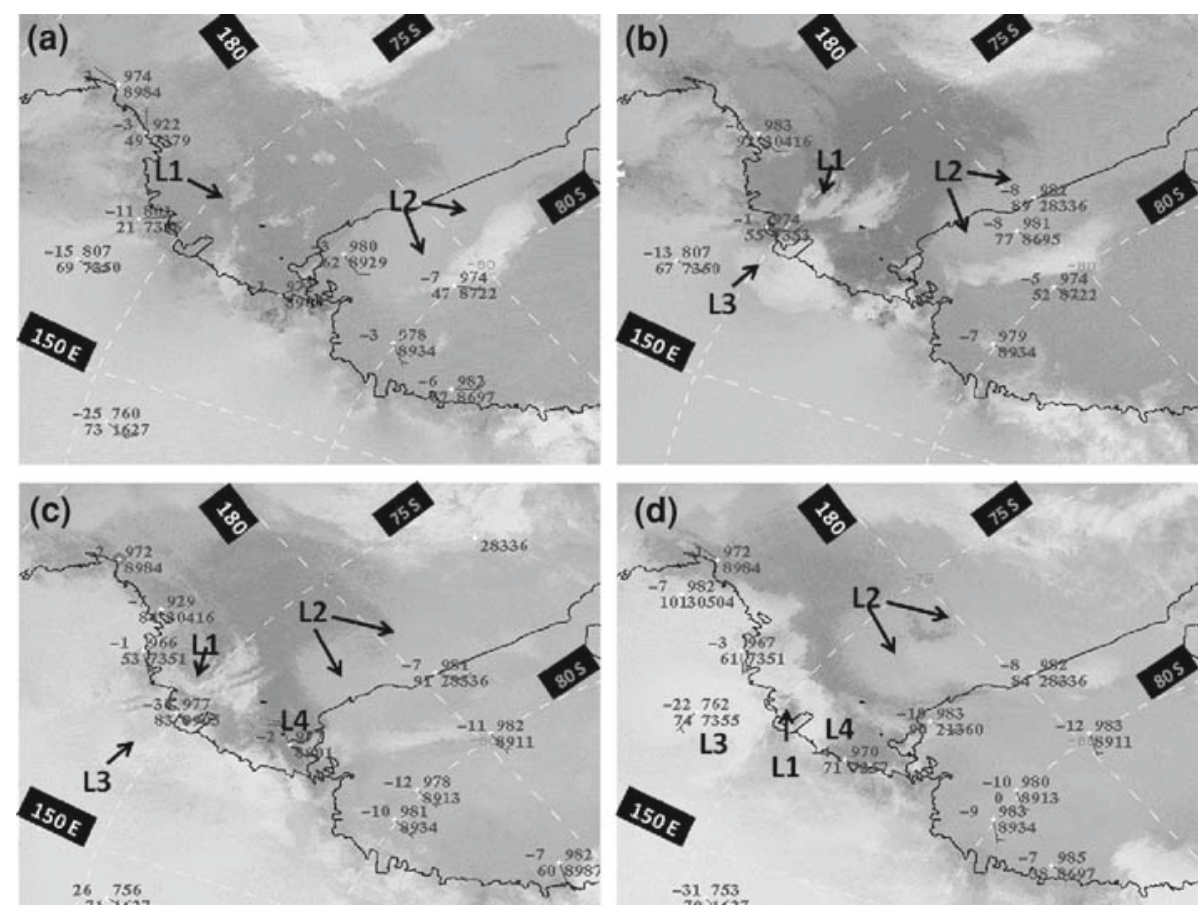

Fig. 2 Thermal infrared composite images from AMRC, a 0000 UTC, b 0600 UTC, c 1200 UTC, d 1800 UTC, January 14, 2007

intensified, manifested as snow showers. High values of negative potential temperature and sea-level pressure differences between Eneide AWS (Terra Nova Bay) and Manuela 8905 AWS (located at Inexpressible Island, David Glacier), in conjunction with the pattern of surface wind at Eneide, attest to the passage of the system (L1) onto the coast. This occurred between 0000 UTC and 0300 UTC, January 15, when frequent snow showers were observed at Terra Nova Bay. A minimal potential temperature difference between Eneide and Mother II AWS at around 0600 UTC, January 15, was the signal that the boundary-layer cold front had travelled across the Ross Sea toward Victoria Land. After the passage of the front, the surface pressure at Terra Nova Bay increased and the south-western barrier wind was soon re-established.

\subsection{Synoptic-Scale Analyses}

Numerical analyses from the European Centre for Medium-Range Weather Forecasting (ECMWF), with a resolution of $25 \mathrm{~km}$, were examined to infer details of the physical processes involved in this case study. From the 12-hourly $500 \mathrm{hPa}$ analyses (Fig. 4a, b, c, d), the synoptic upper level low, centered over the high Plateau, was stretched along Victoria Land as far as the northern coastal area of Wilkes Land, with its centre moving slightly northward. A mobile ridge of high pressure was reinforcing its northern border and advancing southeastward, producing secondary troughs within the main cyclonic circulation. The onset of a short-wave trough, travelling around the synoptic-scale cyclonic circulation across the Ross Sea, tended to isolate as a cut-off over the southern Ross Sea. The pressure at the surface 


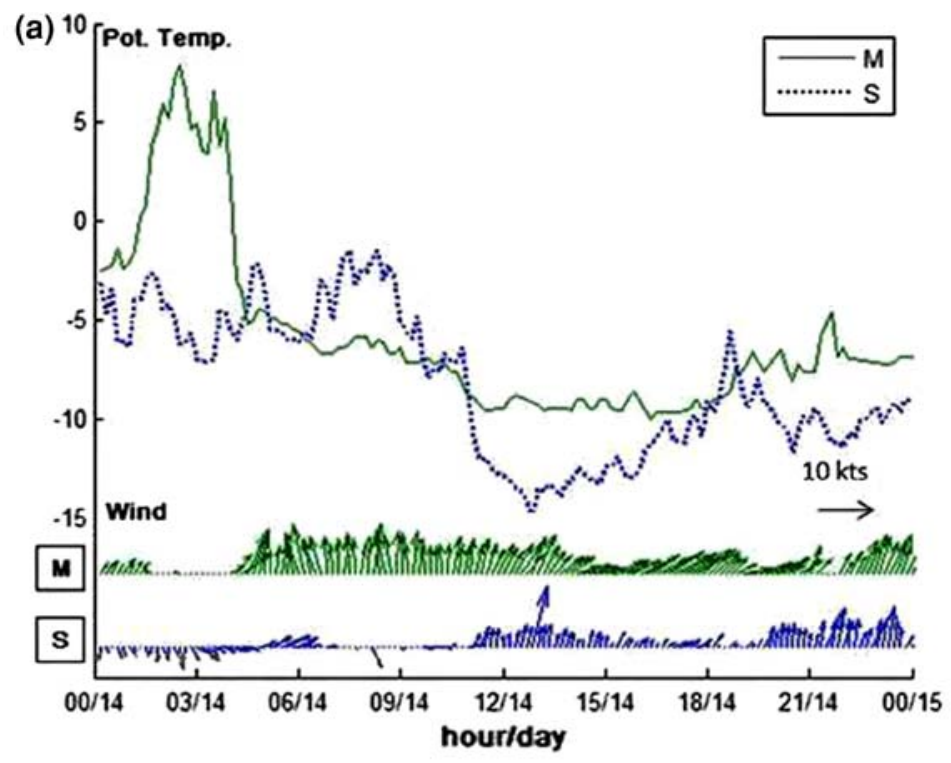

(b) ${ }^{5}$ [Pot. Temp. differe E-ML
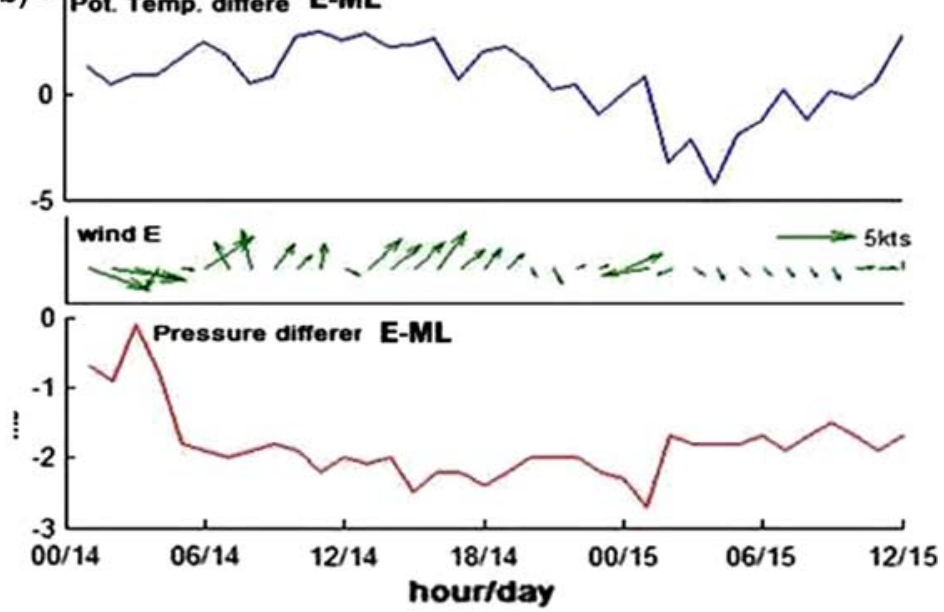

(c) ${ }^{10}$ Pot. Temp. 'difference E-MO

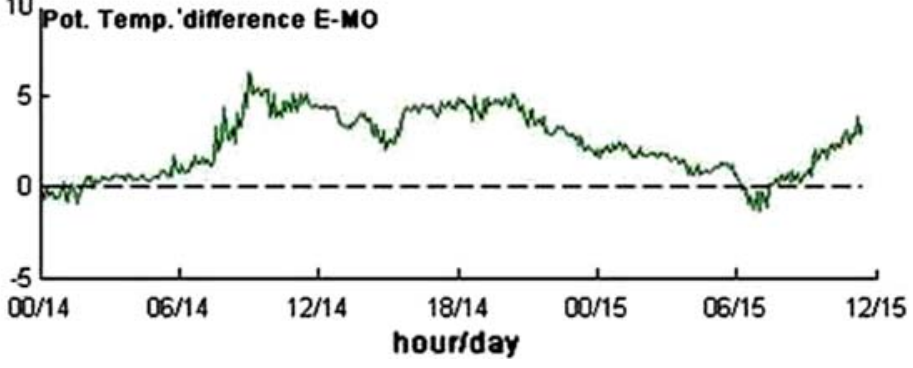

Fig. 3 a time series of potential temperature, wind speed and direction at Marilyn (M) and Schwerdtfeger (S) AWS; b potential temperature difference (blue), pressure difference (red) between Eneide (E) and Manuela (ML) AWS, also plotted is the wind speed and direction (green arrows) at Eneide; $\mathbf{c}$ potential temperature difference (green) between Eneide (E) and Mother II (MO) 

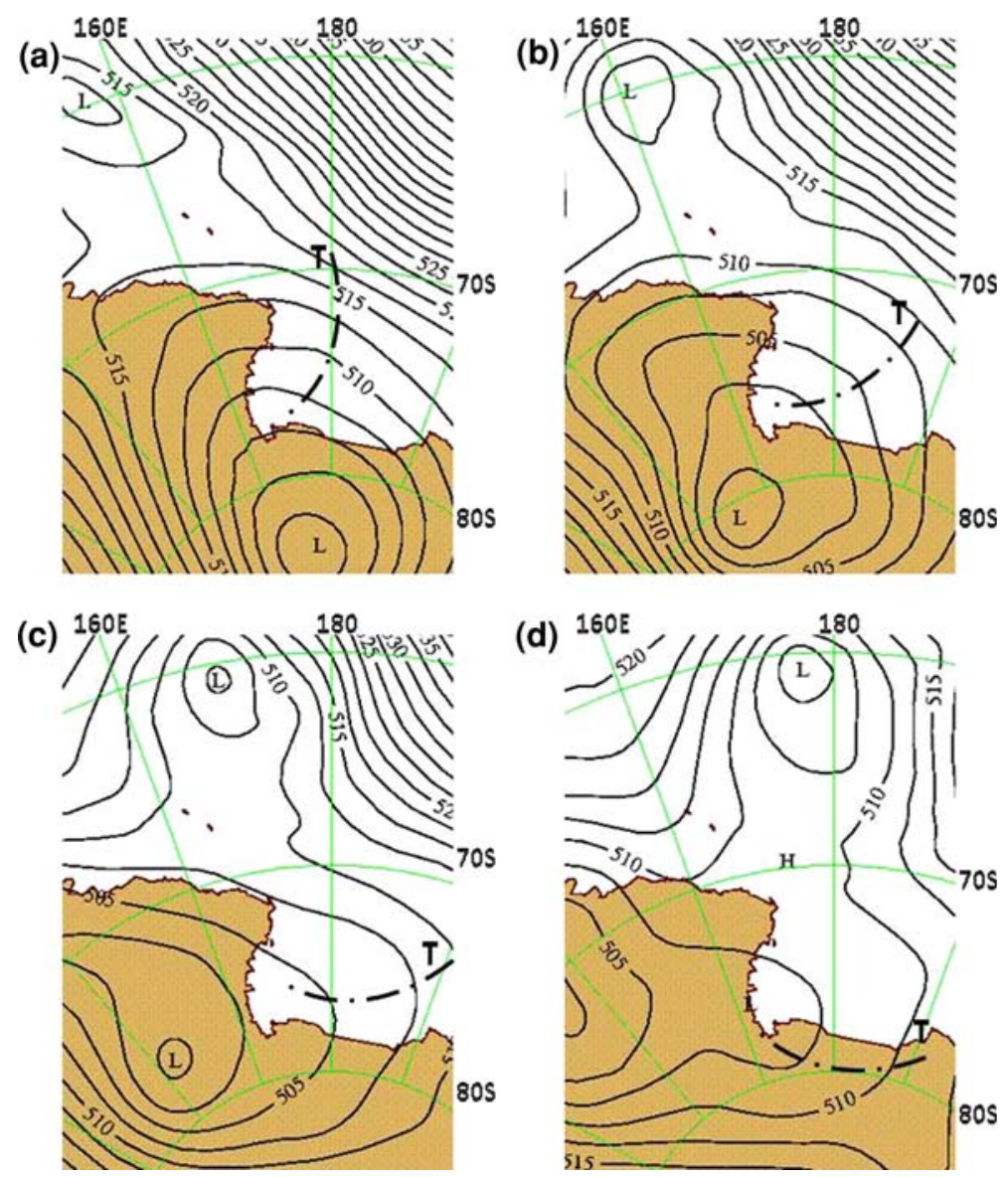

Fig. 4 Upper synoptic analyses. 500-hPa geopotential heights (solid black contours in dam) from ECMWF at 0000 UTC (a), 1200 UTC (b), January 14, 2007 and 0000 UTC (c), 1200 UTC (d), January 15, 2007. 'T' refers to upper level trough

at 0600 UTC, January 14 (Fig. 5a), showed a subsynoptic-scale cyclonic circulation had settled over the western Ross Sea, apparently originating from a decaying synoptic system in the area. Several studies show that the interaction between relatively warm air over the Ross Sea and the katabatic outbreak descending from the high plateau creates favourable conditions for the generation of a baroclinic environment, giving this region a semi-permanent cyclonic circulation where mesoscale cyclones can form (Bromwich 1989b, 1991; Carrasco and Bromwich 1994). A mesoscale baroclinic zone formed along the coast of Victoria Land, south of the Drygalski Ice Tongue, as shown by the potential temperature pattern on the surface (Fig. 5a).

Surface analyses, consistent with the corresponding trace of humidity detected in the satellite image, suggested that maritime warm air was forced over the coastal slopes by the weak easterly flow associated with the surface cyclonic circulation, with the result that moist air was able to reach the interior of Victoria Land. This occured in conjunction with the upper level trough (T) passing through the area, contributing to cyclonic vorticity over the Ross Sea in the middle troposphere. Cyclonic vorticity advection suggests upward synoptic-scale 

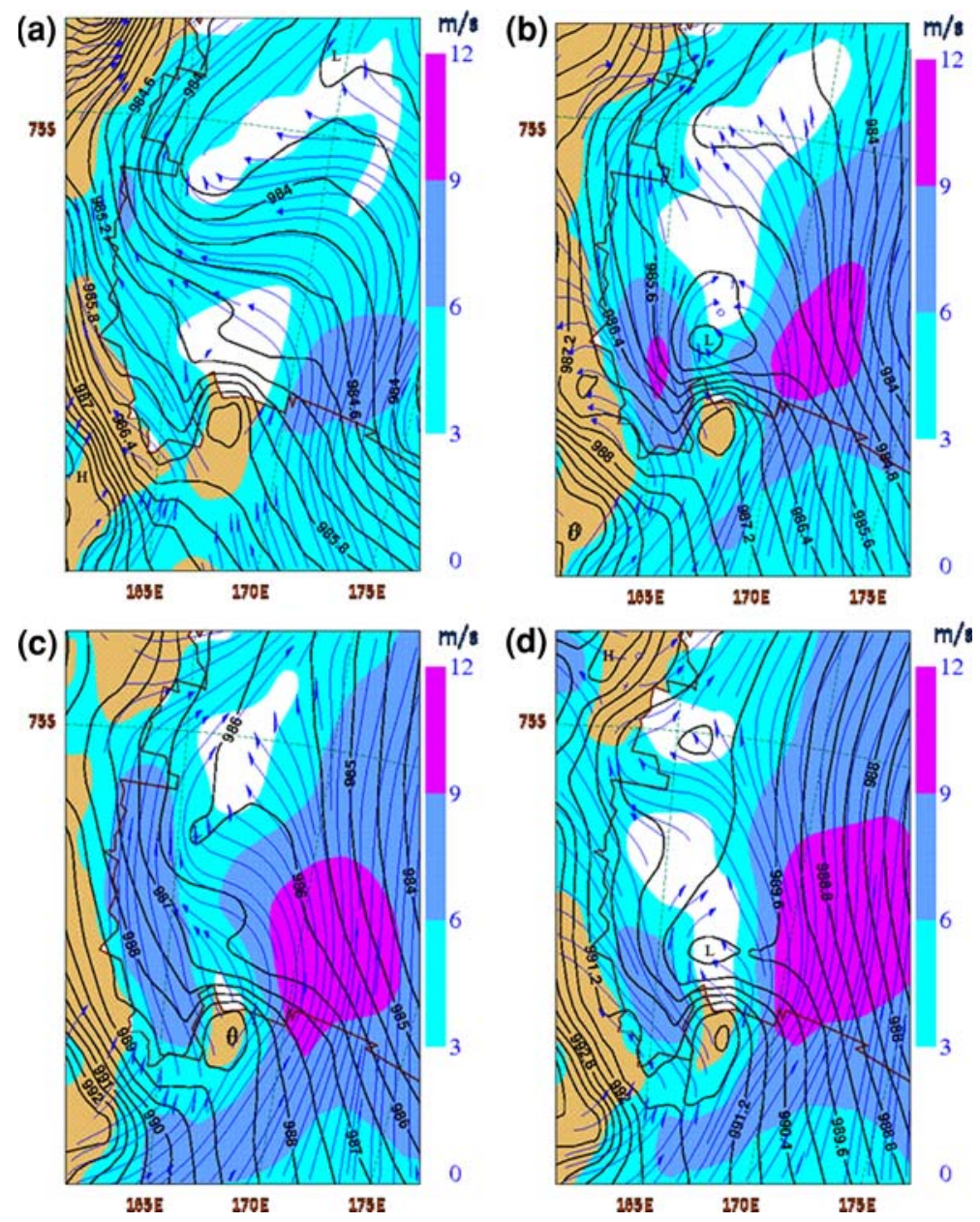

Fig. 5 Mean sea level pressure (black contouring) and surface wind are shown (blue streamlines), starting by 0600 UTC January 14, 2007 (a) up to 0000 UTC January 15, 2007 (d), every 6h. Streamlines show trajectories and shaded colours show scalar average wind speed $\left(\mathrm{m} \mathrm{s}^{-1}\right)$

vertical motion in the lower half of the troposphere that gives synoptic support for triggering the subsequent development of the mesocyclone (L2). The maximum development of the vortex (L2) is confirmed by the surface analyses that show a strengthening (in terms of the increasing pressure gradient) of the cyclonic circulation by 1200 UTC, January 14 (see the sequence in Fig. 5). Upon examining Fig. 5b there is evidence that a small-scale disturbance (L4) has formed on the lee side of Ross Island, although the satellite image does not show a resolvable cloud feature. Strong shear, curvature and stretching vorticity, in a shallow surface layer, due to the cold katabatic air outflowing from the Ross Ice Shelf onto the southwestern Ross Sea constituted the dynamic forcing, leading to mesoscale cyclogenesis (O'Connor and Bromwich 1988; Adams and Tripoli 2003; Monaghan et al. 2005; Slotten and Stern 1987; Steinhaff et al. 2008; Seefeldt et al. 2003). Streamlines in Fig. 5a and b reveal a light to moderate barrier wind abruptly increasing between 1200 UTC and 1800 UTC, 14 January, with the cold air stream splitting around Ross Island, with some of the flow travelling 
to the east and some to the west of the topographic obstacle. Seefeldt et al. (2003) performed high-resolution numerical simulations providing a detailed description of the airflow around Ross Island induced by the complex topography. When stable cold air in the boundary layer moves northward over the north-west region of the Ross Ice Shelf, it piles up on the southern escarpment of Ross Island, creating anomalous pressure gradients that then produce the flow pattern directly connected to the varying terrain and strength of the wind. The acceleration of the katabatic airflow, between 1200 UTC and 1800 UTC, coincided with the strengthening of the surface pressure gradient within the vortex (L2) and its displacement northward. This caused the katabatic drainage to intensify to the east of Ross Island, propagating the boundary-layer cold air farther out over the ice shelf. A boundary-layer baroclinic zone was soon established towards the east of Ross Island by the moderately strong low-level jet, which brought cold continental air into the warmer maritime environment of the Ross Sea. Figure $5 \mathrm{~b}$ suggests that the easternmost branch of the low-level jet splitting around Ross Island curved anticyclonically creating a confluence zone on the eastern edge of the small disturbance (L4). The area where the two opposite circulations converged was characterized by a strong thermal contrast in the lowest levels that could be regarded as a boundary-layer cold front (Fett 1989). At 1800 UTC, 14 January, the boundary-layer cold front, steered by the advancing anticyclonic low-level jet, forced the disturbance (L4) to move north-westward (Fig. 5c), with a transport of negative potential vorticity in the direction of the coast of Victoria Land. A narrow short-wave trough in the surface pressure field, south of Drygalski (Fig. 5c), was elongated in a north-east/south-west direction and orientated orthogonally to the south-easterly surface winds, revealing the location of the boundary-layer cold front. Surface pressure analysis at 1800 UTC showed another baroclinic wave forming in the same zone of strong thermal contrast where the former took place. Six hours later, the small-scale circulation (L4) tended to merge with the vortex (L1), offshore of Terra Nova Bay (Fig. 5d), resulting in a deepening of the cyclonic circulation.

\section{Conceptual Model}

In this section a schematic illustration of the mechanisms that represent the mesoscale cyclogenetic sequence over the Ross Sea is presented. Characteristics of mesoscale vortices observed over the Ross Sea and Ross Ice Shelf suggest that the classic Bjerknes theory is not sufficient to describe the development of such systems, due to its being necessary to take into account the interactions of several airflows involved in the process, all arriving from different air-mass sources (Bromwich 1990, 1991). At 0000 UTC, 14 January, the comma cloud (L1) was forming to the north of a subsynoptic-scale surface low pressure system over the western Ross Sea.

This circulation generated warm air advection against the central Victoria Land enhancing the pre-existing baroclinic region along the coast. At 0600 UTC (Fig. 6a), an intensifying barrier flow from McMurdo Sound, supplied cold air onto the south-western Ross Sea, giving favourable conditions for strong thermal contrast in the low levels over the sea. At 1200 UTC the moderate flow around Ross Island, due to weak large-scale forcing, caused a shallow cyclone to form to the north of the island, where strong curvature and shear vorticity then also contributed to the genesis of this disturbance. Characteristics of mesoscale cyclones in this area reveal that the majority of mesoscale vortices are low cloud features and generally do not exceed the $700 \mathrm{hPa}$ level, due to the prevailing lower-atmospheric stability associated with the enhanced katabatic wind (Carrasco et al. 2003). The relatively warmer maritime air in the lee of Ross Island was absorbed into the circulation and forced to ascend around the 


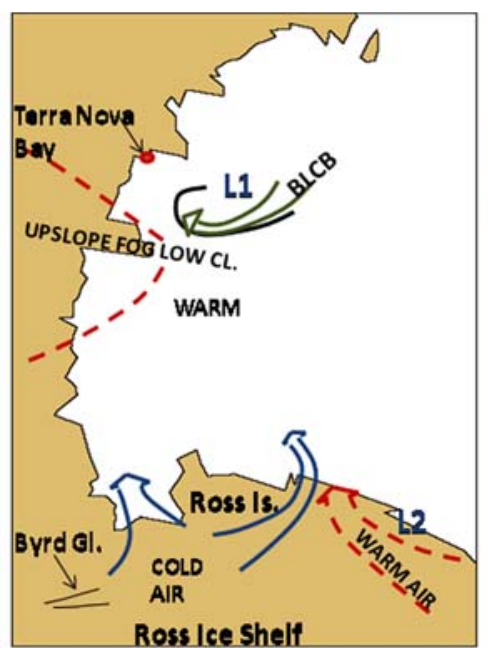

(a)

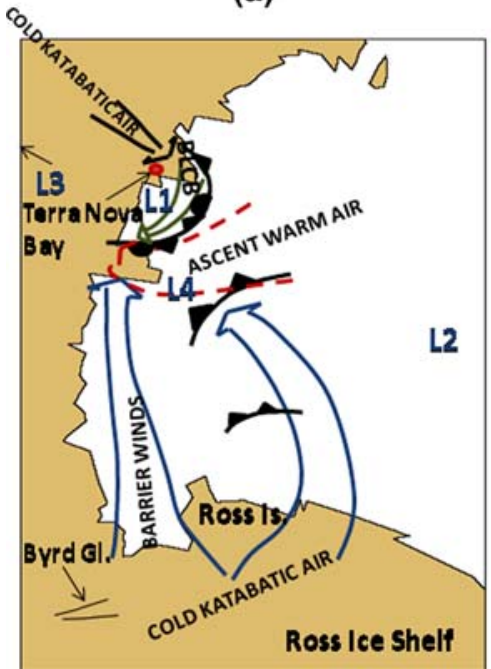

(c)

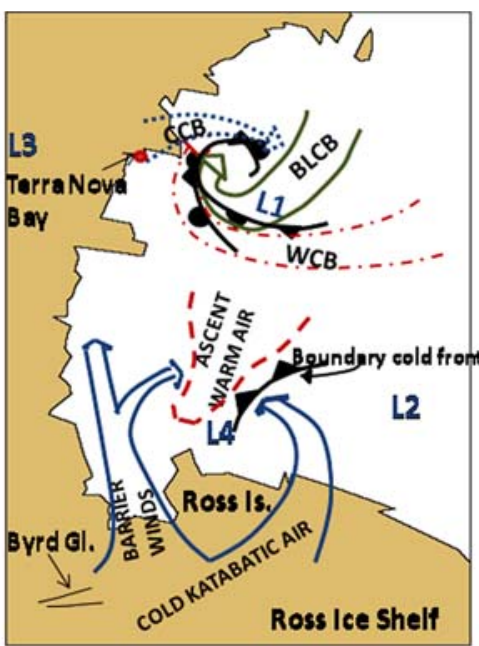

(b)

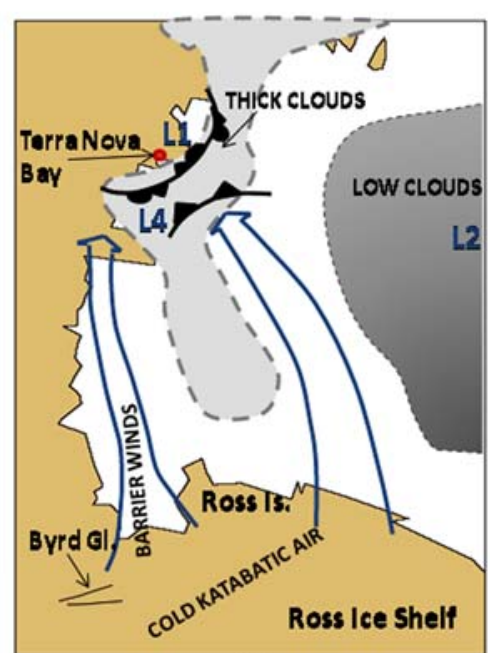

(d)

Fig. 6 Schematic illustration of the conceptual model showing the mechanisms associated with the development of the system L1 and its interaction with the mesoscale boundary cold front crossing the Ross sea. a 0600 UTC, b 1200 UTC, c 1800 UTC, d 0000 UTC, January 14 and 15, 2007. BLCB: Boundary-layer conveyor belt; WCB: warm conveyor belt

centre of the vortex, while a boundary-layer cold front that formed on the eastern branch of the split katabatic flow around Ross Island, approached the small vortex from its eastern edge. The fast moving low-level jet enhanced the thermal contrast on the eastern border of the cyclonic circulation (L4) and dragged new moisture in behind it, increasing latent heat transport and convection.

Subsequently, the boundary-layer cold front turned anticyclonically and undercut part of the ascending warm air that moved while being lifted north-westward. An area of confluence can be seen near the surface as a consequence of the interaction of the two opposite wind 
regimes (Fig. 6b). The increased subsynoptic-scale circulation of the system (L2) to the north-east of the Ross Ice Shelf, in conjunction with an upper level trough passing over the area, enhanced the katabatic drainage and supported the movement of the boundary-layer front north-westward, with the slight anticyclonic curvature forced by the Coriolis deflection. When the airflow passed the tip of Ross Island the Coriolis force (proportional to the wind speed) was not in balance with the pressure gradient force induced by the topography, and so the air stream was gradually deflected to the left, becoming a pseudo-inertial flow. The air stream then encountered a weak pressure gradient with the surface wind conserving its momentum once no topographic effect existed. This is similar to events off the northern tip of the Antarctic Peninsula, where the elimination of the topographically induced pressure gradients result in a transition from a geostrophic to a cyclostrophic balance and the concomitant formation of an anticyclonic jet in the Bransfield Strait (Parish and Schwerdtfeger 1977).

Assuming the induced pressure gradient $F_{p}=0$, the inertial force balance results in:

$$
F_{c}+F_{r}=0
$$

where $F_{c}$ is the Coriolis force and $F_{r}$ is the cyclostrophic force. In natural coordinates with $\mathrm{n}$ directed perpendicular to the flow,

$$
F_{c}=-f V n
$$

and assuming a radius of curvature $R>0$ for anticyclonic flow, then

$$
F_{r}=V^{2} / f R n
$$

Combining (1), (2) and (3) we obtain,

$$
f V=V^{2} / f R,
$$

or

$$
R=V / f^{2}
$$

In this case, by taking into account the maximum values of wind speed in Fig. 5, the anticyclonic radius of curvature (i.e. Rossby radius of deformation) of the inertial trajectory was estimated on the order of $100 \mathrm{~km}$. The anticyclonic deflection of the Coriolis force, without the assistance of a regional pressure gradient, does not explain the observed vigorous katabatic surge propagating for more than $300 \mathrm{~km}$ offshore. A strong and persistent katabatic wind must be sustained by some synoptic or subsynoptic-scale circulation which the katabatic airstream will eventually adjust to, thus becoming geostrophic for some distance. Moreover, the wind should be relatively strong in the direction of the katabatic flow in the low to middle levels of the troposphere in order to ensure a large maximum flux from the continental interior, as is the case in this study. At 1800 UTC the south-easterly moving boundary-layer cold front reached the north-easterly flow caused by the rotation of the comma-head (L1) around the passing surface depression (Fig. 6c). The result of the small disturbance (L4) merging with the system (L1) was a strengthening of the cyclonic circulation, manifested in increasing cyclonic vorticity and vertically thickening cloud. The cloud spiral associated with the deep mesocyclone was turned anticyclonically by the cold air stream, becoming a band of convective cloud elongated in the direction normal to the main flow. 


\section{Summary and Conclusions}

The results of this case study indicate that low-level baroclinicity associated with the movement of a boundary-layer front, in conjunction with strong shear and stretching vorticity, appear to be the main triggering mechanisms leading to the genesis and evolution of a deep mesoscale system. Baroclinic instability and cyclonic vorticity is also required for the development of these polar lows, with theoretical studies demonstrating that baroclinic instability can yield shallow disturbances with sizes and growth rate representative of observed polar lows (Emanuel and Rotunno 1989; Fett 1989).

Katabatic winds have been observed accelerating and propagating horizontally for hundreds of kilometres down the local pressure gradients of synoptic cyclones in a geostrophic direction (Bromwich et al. 1992). In the early stages of the period under investigation, synoptic-scale analyses showed a decaying low pressure system affecting the Western Ross Sea. Associated with this system was a light surface easterly flow offshore from Victoria Land causing warm moist air to dam up against the coastal slopes and flow inland through the David Glacier, establishing an extended interior baroclinic zone. This suggests that such mesocyclones contribute significantly to the transport and accumulation of moisture on the inner Plateau. Initially, two main systems dominated the scenario. Firstly, a mesocyclone approaching Terra Nova Bay from the far north-east with a clear comma-cloud signature, and secondly, another system moving northward to the north-east of the Ross Ice Shelf.

A "surge" of katabatic outflow from the high East Antarctic Plateau descended over the Ross Ice Shelf through the major glaciers and mountain passes, as inferred by the wind pattern and the potential temperature near the surface. The outflow of the barrier wind along the Trans Antarctic Mountains was forced to split into two branches by the high topography of Ross Island. A shallow small-scale disturbance then formed to the lee of Ross Island due to the increasing wind shear and stretching vorticity. Furthermore, the easternmost cold airstream generated a boundary-layer cold front that developed into a mesoscale baroclinic wave, turning initially in a south-easterly direction. The anticyclonic curvature was forced by the ageostrophic flow caused by the absence of the topographically-induced pressure gradient perpendicular to the barrier to the east of Ross Island. An idealized inertial force balance was possible since the background pressure gradient was weak along the trajectory of the airstream curving to the west. As a consequence, a confluence zone was generated on the eastern part of the cyclonic circulation associated with the small disturbance. Baroclinic instability and strong wind shear due to the confluence in the low levels induced negative potential vorticity advection and convection, deepening the cyclonic circulation. The disturbance was then forced by the boundary-layer cold front to migrate across the Ross Sea. Diabatic effects at this stage of development were negligible compared with the baroclinic instability, but may have contributed to further reducing the static stability near the surface, thus facilitating convection. Synoptic-scale support from an upper level trough passing over the area played an important role in triggering subsequent development of the small disturbance. The strengthening of the geostrophic circulation, associated with the main system over the north-eastern Ross Ice Shelf, determined the maximum intensity of the katabatic wind on the eastern side of Ross Island, this in turn permitting the boundary-layer cold front, steered by the leftward turning low-level jet, to propagate farther north-westward across the Ross Sea. During this phase the katabatic flow was highly ageostrophic but then became near-normal to the pressure gradient (i.e. geostrophic) and the Coriolis deflection became less evident. The resharpening of the mesoscale cyclonic circulation offshore of Terra Nova Bay was triggered by its interaction with the small disturbance 
that occurred at the end of day 14. The transition from a shallow cloud spiral to a band of enhanced convective cloud, oriented with the boundary-layer cold front, was a signal of the two systems having merged, which was also confirmed by the numerical analyses. This confirmed that the synoptic environment was favorable to the development of a mesoscale cyclone in just a few hours. The findings of this study suggest that low-level baroclinicity, linked to persistent katabatic outbreaks propagating for long distances over the sea, is an important factor in mesocyclone evolution, leading to strong convection and severe weather conditions.

Acknowledgments Satellite images and AWS data were provided by the Antarctic Meteorological Research Center, University of Wisconsin-Madison (thanks to Matthew Lazzara and Jonas Asuma). Italian AWS data and high resolution satellite images were provided by PNRA-ENEA. We are grateful to Andrea Pellegrini for useful suggestions and contributions. Grid data were obtained from MARS archive (European Centre for Medium-Range Weather Forecast, Reading-UK). Support from the PNRA library is appreciated.

Open Access This article is distributed under the terms of the Creative Commons Attribution Noncommercial License which permits any noncommercial use, distribution, and reproduction in any medium, provided the original author(s) and source are credited.

\section{References}

Adams AS, Tripoli GJ (2003) Use of the UW-NMS to simulate the flow around Ross Island on 3 September 2003. In: Antarctic Automatic Weather Station Annual Meeting, Antarctic Meteorological Research Center Annual Meeting, and Antarctic Mesoscale Prediction System (AMPS) Users' Workshop. Joint Annual Meetings, Charleston, SC, 8-10 June 2004. Preprints. S.1., 2004, pp 20-22

Bromwich DH (1986) Boundary layer meteorology of the western Ross Sea. Antarct J 21(5):237-240

Bromwich DH (1989a) Satellite analyses of Antarctic katabatic wind behavior. Bull Am Meteorol Soc 70:738749

Bromwich DH (1989b) An extraordinary katabatic wind regime at Terra Nova Bay. Antarct Mon Weather Rev 117:688-695

Bromwich DH (1990) Organization of clouds and precipitations in extratropical cyclones. In: Newton CW, Holopainen EO (eds) Extratropical cyclones: the Erik Palmén Memorial volume. American Meteorological Society, Boston, MA, pp 129-153

Bromwich DH (1991) Mesoscale cyclogenesis over the southwestern Ross Sea linked to strong katabatic winds. Mon Weather Rev 119:1736-1752

Bromwich DH, Carrasco JF, Stearns CR (1992) Satellite observations of katabatic wind propagation for great distances across the Ross Ice Shelf. Mon Weather Rev 120:1940-1949

Businger S (1985) The synoptic climatology of polar low outbreaks. Tellus 37:419-432

Carrasco JF, Bromwich DH (1993) Mesoscale cyclogenesis dynamics over the Southwestern Ross Sea, Antarctica. J Geophys Res 98(D7):12973-12995

Carrasco JF, Bromwich DH (1994) Climatological aspects of mesoscale cyclogenesis over the Ross Sea and Ross Ice Shelf regions of Antarctica. Mon Weather Rev 122:2405-2425

Carrasco JF, Bromwich DH (1995) A case study of a midtropospheric subsynoptic-scale cyclone that developed over the Ross Sea and Ross Ice Shelf of Antarctica. Antarct Sci 7(2):199-210

Carrasco JF, Bromwich DH (1996) Mesoscale cyclone activity near Terra Nova Bay and Byrd Glacier, Antarctica during 1991. Glob Atmos Ocean Syst 5:43-72

Carrasco JF, Bromwich DH, Liu Z (1997) Mesoscale cyclone activity over Antarctica during 1991, part 2: near the Antarctic peninsula. J Geophys Res 102(D12):13939-13954

Carrasco JF, Bromwich DH, Monaghan Andrew J (2003) Distribution and characteristics of mesoscale cyclones in the Antarctic: Ross Sea eastward to the Weddell Sea. Mon Weather Rev 131:289-301

Craig G, Cho R (1989) Baroclinic instability and CISK as the driving mechanisms for polar lows and comma clouds. In: Twitchell PT, Rasmussen EA, Davidson KL (eds) Polar and Arctic Lows. A. Deepak, Hampton, VA, pp 131-153

Emanuel KA, Rotunno R (1989) Polar lows as arctic hurricanes. Tellus 41A:1-17 
Fett RW (1989) Polar low development associated with boundary layer fronts in the Greenland, Norwegian, and Barents seas. In: Twitchell PF, Rasmussen EA, Davidson KL (eds) Polar and Arctic Lows. A. Deepak Publishing, Hampton, VA, pp 312-322

Gallée H. (1995) Simulation of mesocyclonic activity in the Ross Sea, Antarctica. Mon Weather Rev 123:20512069

Gallée H. (1996) Mesoscale atmospheric circulation over the southwestern Ross Sea sector, Antarctica. Am Meteorol Soc 35:1129-1141

Heinemann G, Klein T (2003) Simulations of topographically forced mesocyclones in the Weddell Sea and the Ross Sea region of Antarctica. Mon Weather Rev 131:302-316

Monaghan AJ, Bromwich DH, Powers JG, Manning KW (2005) The climate of the McMurdo, Antarctica, region as Represented by One year of forecasts from the Antarctic Mesoscale Prediction System. J Clim 18:1174-1189

Moore GWK, Renfrew IA (2005) Tip jets barrier winds: a quikSCAT climatology of high wind speed events around Greenland. J Clim 18:3713-3725

O’Connor WP, Bromwich DH (1988) Surface airflow around Windless Bight, Ross Island, Antarctica. Q J Roy Meteorol Soc 114:917-938

Parish T, Schwerdtfeger W (1977) A cold low-level jet stream in the Bransfield Strait: an example of inertial flow. Antarct J US 12:171-172

Parish T, Bromwich DH (1987) The surface wind field over the Antarctic ice sheets. Nature 328:51-54

Parish T and Bromwich DH (1988) Mesoscale cyclone interactions with the surface wind field near Terra Nova Bay. Antarct J US 23:172-175

Parish T, Bromwich DH (1991) Continental-scale simulation of the Antarctic katabatic wind regime. J Clim 4:135-146

Rasmussen E (1979) The polar low as an extratropical CISK disturbance. Q J Roy Meteorol Soc 105:531-549

Schwerdtfeger W (1984) Weather and climate of the Antarctic. In: Orvig S (ed) Climate of the polar regions, World Survey Climatology, vol 14. Elsevier, New York, pp 253-355

Seefeldt MW, Tripoli GJ, Stearns CR (2003) A high-resolution numerical simulation of the wind flow in the Ross Island region, Antarctica. Mon Wea Rev 131:435-458

Slotten HR, Stearns CR (1987) Observations of the dynamics and kinematics of the atmospheric surface layer on the Ross Ice Shelf, Antarctica. J Clim Appl Meteor 26:1731-1743

Steinhaff DF, Bromwich DH, Lambertson M, Knuth S, Lazzara MA (2008) A dynamical investigation of the May 2004 McMurdo Antarctica severe wind event using AMPS. Mon Weather Rev 136(1):7-26 